\title{
Rethinking the Practice of Workplace Learning and Development: Utilizing 'Knowledge, Connections and Conversation' in Organizations
}

\author{
Mark Cole, Camden \& Islington NHS Foundation Trust, UK
}

\begin{abstract}
Against the backdrop of a concern that traditional notions of 'training' continue to influence workplace learning and development practice in many organizations, this paper contributes an alternative perspective as a means of engendering change and enhanced performance amongst individuals and across organizations. In discussing the relationships between organizational effectiveness, organization development and learning and development it constructs a 'foundation for improvement' based on three elements: knowledge, connections and conversation. Drawing on illustrative accounts of current L\&D practice from one NHS Trust in the UK, the paper develops what this altered practice of development in a workplace context might look like. Thus, both a vision and a practice agenda, in terms of working differently with people in organizations, are outlined and provide a basis for how fellow practitioners might question and rethink their own L\&D practice.
\end{abstract}

Key Words: training, L\&D, organization development, workplace, practice agenda

\section{Introduction}

Charles Handy has argued that organizational effectiveness (OE) is constructed from over sixty interacting factors (Handy, 1993: 15), including systems and structures, motivation and leadership. This is compounded by the fact that $\mathrm{OE}$ is somewhat imprecisely defined, despite being an active business term for some time. Indeed there exist at least four models attempting to consider it, in respect to analysis and understanding in this regard (Ashraf \& Abd Kadir, 2012). Nevertheless, it is patently an area of focus for many organizations in the current economic climate - and is seen to be a significant way by which firms attain a competitive advantage, particularly where they themselves (and the context in which they work) are complex systems (Right Management, 2010). At least one research study suggests that their “... results highlight the importance of both human resources and employee-oriented processes in explaining and promoting effectiveness" (Ostroff \& Schmitt, 1993).

In this article, the relationship between OE, workforce development and organization development (OD) is explored in a contemporary context, with the aim of espousing a new way of working in an organizational context in order to support systems to work better. The paper seeks to question the dichotomous view of learning and development and OD — but does so from a perspective that is critical of the traditional view of training as a means of engendering change and enhanced performance amongst individuals and across organizations. It explores alternative accounts of practice drawn from the author's experience leading and managing learning and development (L\&D) in the UK's national health service; primarily within the Camden \& Islington (C\&I) NHS Foundation Trust ${ }^{1}$. The paper seeks to contribute insight into what this altered practice of 
development in an organizing context might look like - and how fellow practitioners might rethink their own work from this specific perspective.

\section{Background}

The twentieth century saw three notions constellate in terms of human organizing, namely bureaucracy, Taylorism and Fordism. While 'bureaucracy' has, as a term, acquired negative connotations over time, Max Weber offers a more balanced and sanguine assessment of this organizational form, noting that, through the observance of agreed process and procedure, the possibility of human bias is attenuated (Weber, 1978). Such an organizational model is mirrored by the practice of Taylorism, which encapsulates the notion that oversight is essential in terms of getting the most out of a workforce (Taylor, 1911/1967). The productive arrangements that grew out of that managerialist philosophy are ordinarily described as Fordism, as realized through the introduction of production lines initially in respect to car manufacture in the US (Dassbach, 1991).

All three of these approaches assume an anti-humanist stance: the worker is merely an input to a system, rather than a free acting human agent. Indeed, it is perhaps not insignificant that Taylor started in engineering before moving into the science of management. One of his key early achievements was in the area of the interchangeability of machine parts (Paxton, 2011). His philosophy of scientific management generated a discourse where those working in manufacture could be seen as human capital. As the singer Morrissey said of the rhythm section of the band The Smiths, they were merely "lawnmower parts" (Bret, 2004: 242). Taylor made it possible to think of people in the workplace in this way.

Clearly, it is possible to periodize these linked practices as arising at the back of the nineteenth and the beginning of the twentieth centuries, although it is equally reasonable to say that they were present — to a greater or lesser extent — in manufactory and statecraft prior to this time. Moreover, they persist today, in some quarters, particularly in respect to our global economy: the sweat shops where inexpensive clothing is stitched together are no doubt subject to intense oversight and a productive imperative - and, closer to home, the warehouse of one of the UK's major high street sports retailers has been compared to a Victorian workhouse (Hipwell, 2016).

However, despite these supposed aberrations, we are allegedly now occupying a post-Taylorist, post-Fordist world, where notions such as holacracy (broadly and notionally speaking a system of organizational governance in which authority and decision-making are distributed across selforganizing teams rather than being vested in a management hierarchy) hold sway in terms of the way in which business seeks to organize itself (Bernstein et al., 2016). And so the question forces itself to the foreground: to what extent are our traditional notions of workplace learning and development merely reflections of those early industrial approaches - and was traditional training in such a setting ever truly meaningful, in enhancing the performance of the people and the companies where they worked?

\section{Training in the Workplace}

The way in which training is planned, prepared, delivered and evaluated continues to bear decidedly industrial hallmarks. The process encompasses training needs analysis (TNA), the 
definition of content and delivery methods, and evaluation, with the TNA potentially running at three levels: organization, task, and person (Tannenbaum \& Yukl, 1992: 401-403). Notionally, the TNA is intimately related to the strategy and declared objectives of the business, which presupposes the existence of the sort of sophisticated workforce planning that exists more in word than in deed. Theoretically, the training programmes that are designed address some sort of deficit, particularly in respect to specific individuals or groups of individuals, viz occupational categories or teams.

The very word 'training' — which learning and development struggles to slough off in a business context - has clear connotations: a sports person trains, for example, which often involves repeatedly doing something in order to improve the execution of it. There seems to be something innately repetitive about the idea of 'training', which links it to notions of drilling. In some areas of thought, this links to ideas of "dressage" (Jackson \& Carter, 1998) and the creation of 'docile bodies' (Foucault, 1991) in and through practice in the workplace. And it remains the case - certainly in settings where organizations are heavily regulated, such as health care - that a great deal of what is described as training involves that which carries a statutory or regulatory imperative, with little regard given to whether these experiences are educational, let alone meaningful in day to day practice. Until quite recently, the C\&I NHS Foundation Trust maintained a list of over 50 mandatory training topics. If a newly qualified nurse had complied with this list to the letter, it would have involved more than 15 days away from the workplace in their first year of appointment.

In the traditional notion of workplace learning and development, there is an assumed skills gap which invariably resides in an individual - or a collective of such individuals, who are seeking to deliver a defined outcome. This is supposedly exposed through some sort of skills gap analysis often buried in the wearisome bureaucracy of traditional performance appraisal, a practice that is increasingly being critically interrogated and found wanting (Cappelli \& Tavis, 2016). At an organization wide level, these gaps are notionally unearthed through the training needs analysis, an exercise that is meant to derive from a range of data sources, not least the annual business planning cycle, and which tends to attempt a delicate balance between the empirical and the straightforwardly fictional. Indeed, it is suggested that:

it is interesting to note that whereas most training researchers believe and espouse that trainingneeds analysis is the most important phase in training, this phase remains largely an art rather than a science (Salas \& Cannon-Bowers, 2001: 477).

The imprecision — and, indeed, the illusions around the applicability of a TNA — is partly explained by the fact that, in most instances, it is a supply- rather than a demand-led exercise, which is to say, the assessment of what training might be required at a range of levels in an organization is invariably undertaken by the very people who will deliver the training that is identified as being needed (Chiu et al., 1999). The data sources used to concoct the TNA include workforce plans, personal development plans, and - very often - questionnaires or interview with members of the workforce. Philosophically, what is interesting here is the effacement of the individual in favour of an act of aggregation, where only those needs that are shared by what is judged to be a significant proportion of the workforce (or members of a particular team that has been targeted in this respect) are given value and priority.

The TNA, of course, is just the start of it: the needs identified must then be met and that sees a response in terms of formal training. In 2015, organizations were still predominantly offering on 
the job training and formalized training as the key methods of meeting learning need (Chartered Institute of Personnel and Development, 2015: 9). At the same time, given the high levels of employee and organizational time consumed by such activities, the measurement of effectiveness of those interventions is patchy. The Chartered Institute of Personnel and Development suggest that:

One in seven do not evaluate the majority of their L\&D initiatives - over a third limit their evaluations to the satisfaction of those that take part. One in five assesses the transfer of learning into the workplace and a small minority evaluate the wider impact on the business or society. (Chartered Institute of Personnel and Development, 2015: 4).

Interestingly, the measurement of informal learning is invariably conducted through the prism of organizational goals, while that of formal training is undertaken within its own terms, vis a vis assessing whether a course achieved the objectives that were set for it (Clarke, 2004).

\section{The Foundations of Improvement}

Work undertaken in 2015-16 by the Learning \& Organizational Development Team (L\&OD) at C\&I NHS Foundation Trust in terms of producing an organizational development (OD) strategy helped develop a detailed appreciation of what the individual and organizational needs were in terms of enhancing performance and effectiveness. The diagnostic exercise that offered the foundation for strategic thinking consisted of three phases: semi-structured interviews with the senior leadership team (namely, executive directors plus their deputies and all associate directors, along with professional heads); a thematic analysis of the notes from those conversations, leading to the production of a schedule of issues to be addressed; and facilitated discussions within teams across around $10 \%$ of the workforce.

This diagnostic work was followed by a series of what were called "innovation green housing" events, wherein staff from across the Trust were invited to self-nominate to attend a facilitated event drawing on a specific methodology designed to release creativity and focus on the generation of responses to identified issues (?What If!, 2002). The foundation of this work was the reworked materials from the wider workforce consultation. This was used by the innovation greenhouse attendees to identify issues of concern and to surface exciting ideas to address them, regardless of how outlandish or impractical they might seem. In this regard, the events seek to suspend the normal (and normative) rules and behaviours that apply in the organizational context. There is an extent to which this - and other similar 'techniques of release' — resonate with Bakhtin's notion of the carnival, a time when people are momentarily unrestrained by the ties that bind them on a quotidian basis (Boje et al., 2003). Organizations neglect such carnivalesque experiences at their peril, as they offer a massive opportunity for staff to speak truth to power and give voice to things, such as innovations, that they might otherwise censor in the midst of the normative corporate culture.

Despite the richness and depth of detail that these data offered and the comprehensive strategy that it came to underpin, at root it seemed apparent to those of us who had been involved so intimately in this work that it was founded on three simple elements:

1. Knowledge needs to flow freely and pool where it is required;

2. Connections are critical to making organizations work well, in light of their systemic natures; and 
3. Conversation is the key way to support both the flow of knowledge and the essential connectivity of people.

Delivering on these three essential elements of organizational effectiveness - knowledge, connections and conversation (KCC) - is patently the responsibility of the whole workforce (and crucially of the manager, for whom this focus should be primary in terms of their day to day practice with the people in the workplace), although certain functions within the organization will be charged with supporting and directing interventions that facilitate this. But doing this meaningfully suggests a new way of working in our companies, one where the silo like notions of workforce development, business education, continuing professional development, business analysis, continuous improvement and organization development are transcended. Ultimately, then, any organizational function charged with work around development needs to orient its activity around the notion of KCC. However, it also requires something of a rethink around how current functions, oftentimes discrete, occasionally combined, sometimes felt to be coterminous, support the ambition to meet these specific contextual needs.

\section{Rethinking Organizational Development}

There is an increasing focus in the workplace - and specifically across the Human Resource community - on what is referred to as organizational development (OD). For HR practitioners, they find themselves being driven to focus on the transformational rather than the solely transactional elements of their practice (Ulrich, 1998). In light of this increasing imperative, it is worth pausing to reacquaint ourselves with a helpful definition of OD, as a means of orienting ourselves appropriately for further discussion of how best we might support organizations to work better:

Organization development is an effort (1) planned, (2) organization wide, and (3) managed from the top, to (4) increase organization effectiveness and health through (5) planned interventions in the organization's 'processes' using behavioural-science knowledge (Beckhard, 2006: 3).

Latterly, this domain of organizational practice has developed a fresh strand of activity, one that is less focused on diagnosing and fixing problems - with its notionally empiricist underpinnings - to one that gives total attention to the people in an organization and which uses conversation to facilitate change, using the innate knowledge and talents of those individuals. This dialogic approach has been shown by some of its leading proponents to be defined in contradistinction to the traditional OD practice outlined above, with contrasts emphasized between the positivistic foundations of the diagnostic approach and the interpretive foundations of dialogic OD where organizations are seen as fluid, socially constructed realities that are continuously created through conversations and communication (Bushe \& Marshak, 2015: 14).

This is relevant, insofar as it should be apparent that the dialogic approach to considering how best to develop our organizations is humanistic rather than crudely mechanistic and has a notionally liberal democratic orientation to helping the people in a business to contribute directly to the improvement to that business. In light of this, there would appear to be a significant conflation between dialogic OD and best practice in respect to the workforce development. In particular, it would seem reasonable to conclude that attempts within an organization to address issues of knowledge, connections and conversation between the people therein cannot be thought 
— indeed, should not be thought of - as the preserve of either the L\&D team or the OD team, but should be viewed afresh as a new way of addressing these issues, one that reflects what it means to work in a twenty-first century workplace.

The overlap here between modern ideas of learning in the workplace and what is seen as Dialogic OD is particularly noteworthy. Long before it became fashionable - and, for some advocates of this approach, lucrative — to promote the notion of 70:20:10 in terms of workplace learning with the observation that courses should make up just $10 \%$ of L\&D activity, coaching and such like occupying $20 \%$, and informal and situated learning taking up the bulk of activity in this regard (Jennings, 2011), there were intimations of what learning in and through practice truly looked like. There is an increasingly rich evidence of learning as a multifaceted and organizationally oriented practice, where workforce and organization development is blurred. Thus, for example, we have the insights generated from a study of Xerox engineers, informally discussing their work fixing photocopiers in a diner and thereby exchanging knowledge and ideas (Orr, 1996) leading to notions of knowledge management and communities of practice (Seely Brown \& Duguid, 2000). Similarly, those who build dry stone walls appear to develop intuitive knowledge through practice and by the development of 'rules of thumb' (Farrar \& Trorey, 2008). Other studies such as that of Cook and Yanow's flute makers purport to show how such workers engage in 'organizational learning', learning which is embedded in the practice of work and which is "... neither individuals learning in organizations nor organizations employing processes akin to learning by individuals" (Cook \& Yanow, 1993).

All of which is not to say that L\&D and OD teams simply need to be "merged"; instead, it speaks to a substantive reorientation of thinking where the focus shifts and the way in which development as a thing in itself is addressed differently. The following section explores this in more detail.

\section{Towards a Practice Agenda}

It seems important at this juncture to introduce a subtle shift in thinking from a concentration on 'organization' as the object of our activity to a fresh focus on the general notion and process of 'organizing' as the place where our work might sensibly take place (Weick, 1969). This is a significant conceptual shift, allowing us to turn our backs on the reified notion of an 'organization' that exists outside of the people and relationships that constitute it in favour of an intimate concentration on fluidity, movement and interconnectivity. This is not to blithely assert - as some have - that organization extends beyond structure, although that is a truism, as it presupposes that the 'organization' continues to exist but that it is constituted by a range of less tangible factors alongside the shape it is encouraged to assume (Waterman et al., 1980).

But what might this rethinking of the notion of development in the workplace actually mean for practitioners who are eager to move their focus from a specific concern with training or OD to a wider commitment to organizational improvement? As a practitioner, these are the things that I have begun to do in order to affect that shift - and that I plan to do, in terms of enhancing my practice in the longer term. 


\section{A 'Facilitative' Approach}

First, I am actively working from the premise that knowledge resides in practice - and that practice occurs within an organizing context. For me, the notion of 'pit sense' in the context of mining - an appreciation of safety that is expressed in and through day to day work by those actively engaged in it - is illustrative in this regard. In practice,

pit sense is not acquired through formal training, but is disseminated in situ, experientially, informally, through close social interaction and use of language, and based on the very unambiguous norm of safety. It is also an important part of the self-image and identity of miners, which empowers them to make important decisions away from the direct control of management, thus making them feel safe as well as special (Kamoche \& Maguire, 2010: 726-727).

This has entailed a move away on my part — and that of my team - from programmatic interventions (the design of courses with consideration of content and delivery) to a more facilitative approach that puts greater emphasis on inquiry at the very start of this process. This means that I am offering more bespoke facilitative events, designed from scratch off the back of detailed discussions with managers and staff, and fewer standard courses. Interestingly, this brings its own problems: the NHS staff survey enquires as to whether staff have been able to access continuing professional development - and, for far too many of the respondents, this equates to attendance on a formal course rather than a facilitated event. There is much still to be done to reassure participants that a facilitated event, focused on a matter at hand, represents a rich source of CPD.

However, this shift is vital. US companies across the globe spent close to $\$ 356$ billion in 2015 on employee training and education — but that investment is not seen to deliver anything like the sort of performance improvement and enhanced effectiveness that one would expect (Beer et al., 2016). This failure to deliver a commensurate level of improvement is explained by the fact that companies tend to put the cart before the horse: they assume that learning and development will beget positive change, whereas - in fact - work to create effective change lays the foundation for effective learning insofar as it creates the context in which it can take place (Beer et al., 2016). The conclusion of these authors is simple: "The primary target for change and development is the organization - followed by training for individuals" (Beer et al., 2016: 55).

\section{Working with 'Conversation'}

Second, there is a school of thought that considers conversation as constituting organization (Putnam et al., 2009). Certainly, it is possible to take from this scholarship the notion that conversation occupies a privileged position in organizing, insofar as it offers the key means by which the act of organizing is realized, acts discursively to frame what can and cannot be discussed, and offers the essential material out of which culture - and, indeed, sub-culture appears. Even the ordinarily somewhat dry notion of drafting strategy can be seen to be as a conversational activity, with an argument being made that:

The strategy process, or strategic conversation, has a formal part, designed by the managers, and an informal part, which consists of the casual conversation about the future and which emerges spontaneously in any organization. The latter is extremely important because it determines where people's attention is focused. Managers cannot control this, but they can intervene (van de Heijden, 1996: viii). 
In the cognate realms of knowledge management, business analysis and organizational development, there are myriad techniques to support this type of practice based conversation. Most obviously, a Community of Practice is a key means of creating the space for people to engage around issues in their work domain and work together to address them, primarily by coming together and talking about them (Wenger \& Snyder, 2000). Indeed, this is an area of work where there is considerable focus across the NHS in London, in light of the expectations around the delivery of integrated and place based care (JAMLab, 2016) ${ }^{2}$.

In my current practice, I have arranged a meeting of nearly 100 people from across the NHS in London, all of whom wished to explore the notion of Communities of Practice (CoPs) as a means of engendering vital organizational change from the bottom up. A short film encapsulates the passion, energy, and enthusiasm that was apparent at this gathering, which took place on 3 November 2016: it can be viewed at https:/www.youtube.com/watch? $\mathrm{v}=\mathrm{k} 9 \mathrm{MIwpy} 4 \mathrm{n} 90$. In essence, this method can be reasonably seen as an active refutation of the linear and oppressive notion of organizational change as a staged top-down intervention, perhaps most strongly represented in the work of John Kotter (Kotter, 2012). It seeks to foreground the lived experience of the people in the workplace, using their deep understanding of what goes on there - and what could be done differently and better. Any approach to change other than this - particularly in respect to notions of adjusting culture, which is problematic from a variety of perspectives runs the risk of feeling uncomfortably totalitarian (Wilmott, 1993). This is strongly evidenced by the work undertaken via the Health Innovation Network, which reports on the myriad successes of CoPs around topics of patient safety (Rogers et al., N.D.).

More directive conversational techniques in this regard include methods such as world café (Brown \& Isaacs, 2001) and open space technology (Owen, N.D.), both of which create environments where conversation is key and offers transformational opportunity. Neither is about teaching — or, indeed, about facilitation, in our traditional understanding of that practice. It is about creating a container wherein the lived experience of people within organizations and their practices are an invaluable resource for betterment, development and improvement in this context.

Recently, I was asked to design and run an event for senior nursing leaders to consider how best to get the voice of their profession into the discussions about integration and transformation in health and social care. In discussion with the sponsor in the run up to the session, there were patently a number of implicit expectations in play, namely that a good deal of the time would necessarily be used for presentations by experts and that a key output would be something akin to a project plan. However, I took the view that the crucial thing was for these senior leaders to have a conversation with one another, based upon a focus on inquiry rather than the definition of "problems".

I expressed the opinion that — given the complexity surrounding these deliberations — any traditional GANTT-charted 'action plan' would be illusory and undeliverable to any meaningful degree. Instead, the session eventually involved groups rotating through three stations to hear an "expert" offer an outline assessment and then to discuss the situation. Later in the event, I used the world café approach, which encourages participants to discuss and put their ideas down on a large table cloth: they worked around four questions - and the material captured was rich, candid and detailed, providing the group with a solid foundation on which to proceed.

This experience reinforced for me the notion that I would now take a very similar approach to any notion of learning needs and working to meet them. Few areas of practice are solely about 
knowledge transfer - the requirement that someone digests and acknowledges a new protocol or such like ... and, where they do exist, it is unlikely that formal training is going to affect such a transfer in a meaningful way. One NHS trust comfortably reported high levels of compliance in respect to mandatory training in Safeguarding — but staff could not articulate to the Care Quality Commission $^{3}$ inspectors how a Safeguarding referral might be undertaken. In more sophisticated areas of workplace practice, it would undoubtedly be the case that inviting conversation, through a recognized methodology, could generate far richer results than a traditional 'content plus delivery' training day.

The use of methods such as these - and the embedding of new conversational practices within the warp and weft of our organizations, such as the encouragement of thinking environments throughout an organization through the adoption and promotion of a methodology such as Time To Think (Kline, 1999) — offer the opportunity for immediately helpful interventions around live issues, as well as a longitudinal encouragement for people in organizations to do things differently over time. They offer small "climatological" shifts that potentially will connect and amplify their effect through that connectivity in order to reshape the overall culture of a place of work. And we need to go further, in terms of creating spaces for conversation and dialogue, as some companies have; enhancing the ways in which people use words to offer feedback and undertake reflection, and using scenarios for people to make sense of their work through stories (April, 1999).

Just recently, I was working with a large London NHS trust, eager to undertake work in a specific area of process in order to enhance their efficiency. Pace and scale was determined by a number of external imperatives, as well as the need to rework the balance between demand and supply. Alongside this, there was a strong commitment to engage with their workforce in this regard. Now, my opinion is that organizations tend to sit on a continuum in this regard between staff involvement and true staff engagement, with the former being primarily about communication strategies and the latter about that workforce being seen as a key contributor to the health and wellbeing of the organization. In light of the issue they faced and a more general commitment on my part to change arising out of lived experience rather than delivered from above, I was keen that this work should sit at the engagement end of the scale, rather than seeing the workforce as a knowledge resource to be activated and then decommissioned shortly afterwards in respect to focus around a specific activity.

The events undertaken attracted 'enthusiasts' from across the trust — by which was meant, anyone who was committed to doing things differently and improving the organization, from whatever perspective - and used the Time To Think methodology. Not only did this intervention generate a truly meaningful list of changes and projects in order to improve process, it also acknowledged the staff and their contribution - and allowed them to own the ideas and commit to them in an authentic way. To that extent, it unpicked that traditional view of changes being designed, cascaded downwards, and staff often being "trained" to come to terms with those changes.

\section{Inquiry Based Intervention}

Third, I work differently in terms of assessing how best to intervene when discussions of development occur in an organizational context. As noted above, the encouragement of Communities of Practice (JAMLab, 2016) is a key way by which to support the personal, 
professional and organizational development of an organization as well as providing strong support for activities such as secondment to focused project groups and to events within the organization itself, such as internal 'organizational raids' and 'randomized coffee trials'. 'Organizational raids' provide half day or day long exposure to another organization's knowhow (in this case another section of the C\&I NHS Trust). They are purpose-built to allow one organization to learn from another's expertise and proven practice (Whitehall \& Industry Advisory Group, 2016). Randomized coffee trials are a rather fancy name for a simple idea. They are used to connect people in an organization at random and give them time to meet to have a coffee and talk about whatever they wish (Soto, 2013). For me, then, my practice has shifted. I see each request for support from within the organization not as a problem to be solved but as a line of inquiry that needs to be explored, both by me but - more importantly — by all of those implicated in the idea that there is some deficit that needs to be addressed. So, I respond less in terms of drafting content and considering how best it might be delivered - and more around drilling into the issue that underlies a request for support, an action that I seek to undertake alongside those implicated in it. To that extent, it underscores the way in which I describe my workplace nowadays, which is that I help people to see and understand things hidden in plain sight; key to that, in my mind, is the deployment of conversation rather than pedagogy.

\section{Conclusion}

The convergence of bureaucracy, Taylorism and Fordism arose in respect to industrial and commercial organizing early in the twentieth century. This paper has argued that this triumvirate still shapes our thinking and practice in an organizational context today, even though economic circumstances have drastically changed. A key element that underpins these three is the notion of routinization, which was a feature of many working lives at the time that they emerged but which is now viewed negatively, insofar as there is a greater emphasis now on the importance of competitive advantage through change and innovation. Our absorption at a quotidian workplace level in the routine of our work can lead to a supposition that novelty is necessarily and causally preceded by event (Human, 2015), an underpinning that might reasonably be seen as structuring at a deep level our notions of development in respect to workplace learning. ${ }^{4}$ That is to say, by making a connection between an event and a newness of approach, we may end up labouring under the misapprehension that freshness of vision and application of new skills in practice are achieved exclusively through a transformative event, specifically in this instance the delivery of content via a 'training course'. This disregards the evolutionary shifts and changes that occur as part of that routinized practice, which appear in the course of that day to day work rather than through an individual being drawn out of it and placed in a new context — or through some significant happening that distorts the warp and weft of our regular workplace activity.

Moreover, it has been argued herein that these events are significantly less effective than is ordinarily imagined in a business context, despite our continued investment of time and money in the practice of offering training. In contrast to this, the paper has argued in favour of a focus on enhancing organizational effectiveness in its widest possible sense rather than becoming too embroiled in siloed discussions of workforce development and organizational development. In essence, it is posited, the focus should be on development within the frame of human organizing, with a practice that is committed to enhancing knowledge flow, purposeful conversation and connection between people, within firms and across systems. 
Whilst such notions might seem intangible — and hence traditional workforce or organizational development would be more reassuring, in terms of defined interventions that carry with them a positivistic measurability - the final section of this paper has detailed how the author - as a practitioner in situ - has endeavoured to work differently in a range of contexts and through a variety of methods, in order to be exemplary in his work and to offer a vision of working differently with people in organizations to the mutual benefit of all.

\section{Notes}

1 An NHS trust is a provider organization, responsible for delivering services. They are the principal means by which healthcare provision in the UK is delivered. A trust, in effect, is a public sector corporation, with some enjoying what is described as Foundation status, which affords them even greater autonomy to act in respect to employment practices and financial governance.

2 There is an imperative in health and social care to work in a more integrated way, ensuring that services from these previously relatively discrete sectors mesh together and wrap meaningfully around the user - and do so in a way that enhances quality of care and experience while, at the same time, ensuring improved cost effectiveness. The vision for this can be found in the NHS England document entitled Five Year Forward View, which appeared in October 2014 and can be found on the Department of Health website at https://www.england.nhs.uk/ourwork/futurenhs/ [Accessed 16 February 2017].

3 The independent regulator of health and social care in England.

4 Elsewhere, the very notion of event has been interrogated critically, explored from a range of perspectives and found to be problematic in terms of the way in which we structure our thinking about human experience and life in a social context (Zizek, 2014).

\section{References}

?What If! (2002). Sticky wisdom: How to start a creative revolution at work. Oxford: Capstone.

April, K. A. (1999). Leading through communication, conversation and dialogue. Leadership and Organization Development Journal, 20(5): 231-241.

Beckhard, R. (2006). What is organization development?. In: J. V. Gallos, ed. Organization development. San Francisco: Jossey-Bass, pp.3-12.

Beer, M., Finnstrom, M., \& Schrader, D. (2016). Why leadership training fails — and what to do about it. Harvard Business Review, 94(10): 50-57.

Bernstein, E., Bunch, J., Canner, N., \& Lee, M. (2016). Beyond the holacracy hype. Harvard Business Review, 94(7/8): 38-49.

Boje, D. M., Luhman, J. T. \& Cunliffe, A. L. (2003). A dialectic perspective on the organization theatre metaphor. American Communication Journal, 6(2).

Bret, D. (2004). Morrissey: Scandal and passion. London: Robson.

Brown, J., \& Isaacs, D. (2001). The World Cafe: Living knowledge through conversations that matter. The Systems Thinker, June/July, 12(5): 1-5.

Bushe, G. R., \& Marshak, R. J. (2015). Introduction to the dialogic organization development mindset. In: G. R. Bushe \& R. J. Marshak, eds. Dialogic organization development: The theory and practice of transformational change. Oakland, CA: Berrett-Koehler Publishers Inc, pp.11-32.

Cappelli, P. \& Tavis, A., 2016. The performance management revolution. Harvard Business Review, October.

Chartered Institute of Personnel and Development (2015). Learning and development 2015: Annual survey report, London: CIPD.

Chiu, W., Thompson, D., Mak, W.-m., \& Lo, K. L. (1999). Re-thinking training needs analysis: A proposed framework for literature review. Personnel Review, 28(1/2): 77-90.

Clarke, N. (2004). HRD and the challenges of assessing learning in the workplace. International Journal of Training and Development, 8(2): 140-156. 
Cook, S. D. N., \& Yanow, D. (1993). Culture and organizational learning. Journal of Management Inquiry, December, 2(4): 373-390.

Dassbach, C. H. A. (1991). The origins of Fordism: The introduction of mass production and the five-dollar wage. Critical Sociology, 18(1): 77-90.

Farrar, N., \& Trorey, G. (2008). Maxims, tacit knowledge and learning: Developing expertise in dry stone walling. Journal of Vocational Education \& Training, 60(1): 35-48.

Foucault, M. (1991). Discipline and Punish: The Birth of the Prison. London: Penguin.

Handy, C. B. (1993). Understanding organizations. 4th ed. Harmondsworth: Penguin.

Hipwell, D. (2016). Sports Direct "is like a Victorian workhouse". The Times, 22 July, p.14.

Human, O. (2015). Potential novelty: Towards an understanding of novelty without an event. Theory, Culture \& Society, 32(4): 45-63.

Jackson, N., \& Carter, P. (1998). Labour as dressage. In: A. McKinlay, \& K. Starkey, eds. Foucault, Management and Organization Theory: From Panopticon to Technologies of the Self. London: Sage.

JAMLab (2016). Communities of Practice for systems leadership. [Online] Available at: http://www. londonleadershipacademy.nhs.uk/sites/default/files/COP\%20handout\%20May\%202016.pdf [Accessed 6 October 2016].

Jennings, C. (2011). Social \& Workplace Learning through the 70:20:10 Lens. [Online] Available at: http://charles-jennings.blogspot.co.uk/2011/08/social-workplace-learning-through.html [Accessed 14 September 2016].

Kamoche, K., \& Maguire, K. (2010). Pit sense: Appropriation of practice-based knowledge in a UK coalmine. Human Relations, 64(5): 725-744.

Kline, N. (1999). Time to think: Listening to ignite the human mind. London: Cassell.

Kotter, J. P. (2012). Leading Change. Cambridge, Mass: Harvard Business Review Press.

Orr, J. E. (1996). Talking about machines: An ethnography of a modern job. Ithaca: ILR.

Ostroff, C., \& Schmitt, N., 1993. Configurations of organizational effectiveness and efficiency. Academy of Management Journal, 36(6): 1345-1361.

Owen, H. (N.D.). A brief user's guide to open space technology. [Online] Available at: http://www. chriscorrigan.com/parkinglot/wp-content/uploads/2008/08/Original-Users-Guide-smaller.pdf [Accessed 6 October 2016].

Parent, D., Sloan, N., \& Tsuchida, A. (2015). Performance management: The secret ingredient. In: J. Bersin, D. Agarwal, B. Pelster, \& J. Schwartz, eds. Global Human Capital Trends 2015: Leading in the new world of work. s.l. Deloitte University Press, pp.50-58.

Paxton, J. (2011). Taylor's unsung contribution: making interchangeable parts practical. Journal of Business and Management, 17(1): 75-83.

Putnam, L. L., Nicotera, A. M., \& McPhee, R. D. (2009). Introduction - Communication constitutes organization. In: L. L. Putnam, \& A. M. Nicotera, eds. Building theories of organization: The constitutive role of conversation. New York: Routledge, pp.1-20.

Right Management (2010). Organizational effectiveness: Discovering How to Make It Happen, Philadelphia: Right Management.

Rogers, M., Joel, K., \& Ream, M. (N.D.). Patient safety communities of practice at HIN; Leading change across system boundaries, London: Health Innovation Network South London.

Salas, E., \& Cannon-Bowers, J. A. (2001). The science of training: A decade of progress. Annual Review of Psychology, Volume 52: 471-499.

Seely Brown, J., \& Duguid, P. (2000). The social life of information. Boston: Harvard Business School Press.

Soto, M. (2013). Institutionalising Serendipity via Productive Coffee Breaks. [Online] Available at: http:// www.nesta.org.uk/blog/institutionalising-serendipity-productive-coffee-breaks [Accessed 11 October 2016].

Tannenbaum, S. I. \& Yukl, G., 1992. Training and development in work organizations. Annual Review of Psychology, Volume 43: 399-441.

Taylor, F. W. (1911/1967). Principles of scientific management. New York: Norton.

Ulrich, D. (1998). A new mandate for HR. Harvard Business Review, January-February: 124-134. 
van de Heijden, K. (1996). Scenarios: The art of strategic conversations. Chichester: John Wiley.

Waterman, R. H., Peters, T. J., \& Phillips, J. R. (1980). Structure is not organization. Business Horizons, June: $14-26$

Weber, M. (1978). Economy \& Society: An Outline of Interpretive Sociology. Berkeley: University of California Press.

Weick, K. (1969). The social psychology of organizing. Reading MA: Addison-Wesley.

Wenger, E. C., \& Snyder, W. M. (2000). Communities of Practice: The organizational frontier. Harvard Business Review, Jan/Feb: 139-145.

Whitehall \& Industry Advisory Group (2016). Organizational Raids. [Online] Available at: https://www. wig.co.uk/leadership-development/for-your-organisation/organisational-raids.html [Accessed 11 October 2016].

Wilmott, H. (1993). Strength is ignorance; slavery is freedom: Managing culture in modern organizations. Journal of Management Studies, 30(4): 515-552.

Zizek, S. (2014). Event. London: Penguin Random House UK.

\section{The Author}

Mark Cole is Head of Learning and Organizational Development at Camden \& Islington NHS Foundation Trust. He is currently seconded to the London Leadership Academy, where he is undertaking work on systems leadership. He is a Chartered Member of Chartered Institute of Personnel and Development and has experience in both HR development and management. Mark attained his doctorate at the University of Greenwich in 2012, where his thesis explored reflective practice in health care from a Foucauldian perspective. More recently, he has completed a PostGraduate Certificate in Organizational Change Management at the University of Southampton. His particular interests are experiential learning and leadership development — and he describes his practice as seeking to help people in organizations to see and to understand things that are hidden in plain sight. 